\title{
Combined effects of water film thickness and paste film thickness on rheology of mortar
}

\author{
A. K. H. Kwan • L. G. Li
}

Received: 8 February 2011 / Accepted: 18 January 2012/Published online: 6 February 2012

(C) The Author(s) 2012. This article is published with open access at Springerlink.com

\begin{abstract}
In the mortar portion of a concrete mix, the water must be more than sufficient to fill the voids between the solid particles of cement and fine aggregate whereas the paste volume must be more than sufficient to fill the voids between the solid particles of fine aggregate so that there will be excess water to form water films coating all the solid particles and excess paste to form paste films coating the fine aggregate particles. Hence, it may be postulated that the water film thickness (WFT) and the paste film thickness (PFT) have major effects on the rheology of mortar. In this study, the combined effects of WFT and PFT on the rheology, cohesiveness and adhesiveness of mortar were investigated by testing mortar samples with varying water, cement and aggregate contents. It was found that whilst the WFT is the single most important factor governing the rheology of mortar, the PFT also has significant effects. Particularly, the PFT has certain interesting effects on the cohesiveness and adhesiveness of mortar, which should be duly considered in mortar design.
\end{abstract}

\footnotetext{
A. K. H. Kwan $(\bowtie) \cdot$ L. G. Li

Department of Civil Engineering,

The University of Hong Kong,

Hong Kong, China

e-mail: khkwan@hku.hk

L. G. Li

e-mail: ligu123@msn.com
}

Keywords Flowability .

High-performance concrete $\cdot$ Paste film thickness · Rheology $\cdot$ Water film thickness

\section{Introduction}

With the advent of modern chemical and mineral admixtures, it is now possible to produce many different types of high-performance concrete (HPC) with high performance in certain attributes at the fresh or hardened state [1]. However, the mix design of HPC, especially those containing many ingredients, is not an easy task. In this regard, it is proposed herein to develop a three-tier system for the mix design of HPC and concrete in general. The first tier of materials consists of the cementitious materials and microfillers of size smaller than or similar to cement. These materials will, after mixing with the water, form a paste for filling the voids in the next tier of materials. The second tier of materials consists of the fine aggregate particles and fillers of size smaller than or similar to fine aggregate. These materials will, after mixing with the paste, form a mortar for filling the voids in the next tier of materials. Finally, the third tier of materials consists of the coarse aggregate particles. With the concrete regarded as a three-tier system, the mix design may then be carried out by considering successively the paste and mortar portions of the concrete. 
This paper focuses on the mortar portion of concrete. While considering the mortar portion, it should be borne in mind that a layer of mortar, which has to be sufficiently thick and flowable, should be provided to coat every coarse aggregate particle [2] and the fresh properties of a concrete are closely related to the rheology of its mortar portion [3, 4]. For self-consolidating concrete (SCC), it has been suggested that the mortar portion should be designed first $[5,6]$. Since a SCC has to flow a long distance and fill into far-reaching corners without segregation, the mortar portion has to have high flowability [3-6] and high cohesiveness [5-7]. Furthermore, the mortar portion needs to have high adhesiveness (the ability to adhere to solid surfaces) so as to avoid separation of the mortar from the coarse aggregate particles or in the case of mortar works from the substrate. However, the desired high flowability, cohesiveness and adhesiveness are not easy to achieve at the same time. One reason is that the addition of a superplasticizer (SP) to increase the flowability would substantially decrease the cohesiveness [8] and probably also the adhesiveness. Besides, although mortar with high adhesiveness has been used in concrete repair and brick works [9-11], a suitable test method for measuring the adhesiveness of mortar is still lacking.

A number of studies have been carried out to identify the main factors affecting the rheology of mortar. Banfill [12] found that both the yield stress and viscosity of mortar decrease exponentially with the water content. In other studies, it has been found that the characteristics of the fine aggregate also have significant effects. For example, De Schutter and Poppe [13] showed that the water demand of a mortar is closely related to the packing density of the fine aggregate. Reddy and Gupta [14] found that generally a mortar made of a finer sand would need a higher water content for a given workability and explained that this is because of the larger solid surface area of the finer sand used. From these studies, it may be inferred that the main factors affecting the rheology of mortar are the water content, packing density and solid surface area of the solid-water mixture. At a smaller particle size scale, Kwan and Wong [15] demonstrated that blending of cement with condensed silica fume could increase the packing density, decrease the amount of water needed to fill the voids and thus increase the flowability of the paste formed. Hence, both the packing density of the fine aggregate and the packing density of the cementitious materials should have some effects on the rheology of mortar.

However, there have been many problems with the measurement of packing density. The conventional dry packing methods, such as those stipulated in British Standard BS 812: Part 2: 1995 and Eurocode EN1097-4: 1999, are not really suitable for cementitious materials and fine aggregate, which tend to form agglomerates under dry condition. Moreover, the packing density so measured is very sensitive to the amount of compaction applied [16]. To resolve these problems, the author's research group has recently developed a new method, called the wet packing method, for measuring the packing densities of cementitious materials [17], fine aggregate [18] and cementitious materials plus fine aggregate [19]. This wet packing method has the advantages that it is capable of simulating the actual wet condition in fresh cement paste or mortar and allowing for the presence of any SP, which may have significant effects on the packing density. Using this wet packing method, a series of studies have been conducted to evaluate the combined effects of water content, packing density and solid surface area on the rheology of cement paste [20, 21] and mortar [22-24]. The test results obtained so far indicated that the combined effects of water content, packing density and solid surface area may be evaluated in terms of the water film thickness (WFT) of the solid-water mixture and that the WFT is the single most important factor governing the rheology of paste and mortar.

Relatively, the case of mortar is more complicated than the case of paste. Although in both cases, the WFT is proven to be the single most important factor governing the rheology, in the case of mortar, the characteristics and amount of fine aggregate also have some effects. These influences of the fine aggregate may be interpreted as the indirect effects of the characteristics and amount of fine aggregate on the thickness of the paste films coating the fine aggregate particles. Early in the 1940s, Kennedy [25] advocated that the paste has to be more than sufficient to fill the voids between the aggregate particles so that there would be excess paste to provide a thin film of paste coating each and every aggregate particle to lubricate the concrete mix. Then in the 1960s, Powers [26] proposed the excess paste 
theory that only the excess paste is contributing to workability and if the packing density of the aggregate could be maximized, the amount of paste needed to fill voids and produce a certain required workability would be minimized. Later, in 1999, Oh et al. [27] attempted to incorporate the paste film thickness (PFT) in the mix design of SCC. However, due to the lack of a suitable method for determining the packing density of fine particles and the lack of studies on the correlation between the PFT and the rheology of mortar and concrete mix, little progress has since been made.

It is the authors' belief that although the WFT should remain the governing factor influencing the rheology of paste, mortar and concrete, the PFT should also have certain effects. Quite possibly, the effect of WFT is dependent on the PFT and the effect of PFT is dependent on the WFT. In the present study, the concepts of WFT and PFT are integrated together to investigate the combined effects of WFT and PFT on the rheology of mortar. For the investigation, an experimental program was launched, wherein mortar samples with different combinations of cement/aggregate $(C / A)$ ratios and water/cement $(W / C)$ ratios were made for testing. The rheological properties of each mortar sample were measured in terms of flow spread, flow rate, yield stress and apparent viscosity, whereas the packing density, cohesiveness and adhesiveness were measured using the wet packing method, sieve segregation test and a new stone rod adhesion test developed herein.

\section{Determination of WFT and PFT}

To determine the WFT of a mortar sample, it is necessary first of all to measure the packing density of the solid particles in the mortar (including the cement and fine aggregate). From the packing density of the solid particles $\tau$ (defined as the ratio of the solid volume to the bulk volume of the particles), the voids ratio of the solid particles $u$ (defined as the ratio of the voids volume to the solid volume of the particles) can be evaluated as:

$u=\frac{1-\tau}{\tau}$

Having evaluated the voids ratio, the excess water ratio $u_{\mathrm{w}}^{\prime}$ (defined as the ratio of the volume of excess water to the solid volume of the particles) can be obtained as:

$u_{\mathrm{w}}^{\prime}=u_{\mathrm{w}}-u$

where $u_{\mathrm{w}}$ is the water ratio (defined as the ratio of the volume of water to the solid volume of the particles). On the other hand, the specific surface area of the solid particles $A_{\mathrm{M}}$ (defined as the solid surface area per unit solid volume) is given by:

$A_{\mathrm{M}}=A_{\mathrm{C}} \times R_{\mathrm{C}}+A_{\mathrm{FA}} \times R_{\mathrm{FA}}$

in which $A_{\mathrm{C}}$ and $A_{\mathrm{FA}}$ are respectively the specific surface areas of cement and fine aggregate, and $R_{\mathrm{C}}$, and $R_{\mathrm{FA}}$ are respectively the volumetric ratios of cement and fine aggregate to the total solid volume. With the values of $u_{\mathrm{w}}^{\prime}$ and $A_{\mathrm{M}}$ so determined, the WFT, which has the physical meaning of being the average thickness of the water films coating the solid particles, may be obtained as:

$\mathrm{WFT}=\frac{u_{\mathrm{w}}^{\prime}}{A_{\mathrm{M}}}$

The steps for determining the PFT of a mortar sample are similar. However, since the fine aggregate may contain particles smaller than $75 \mu \mathrm{m}$, which tend to be intermixed with the cement to become part of the paste, there is a necessity to redefine the paste. Herein, it is suggested to redefine the paste as the powder paste containing water and all particles smaller than $75 \mu \mathrm{m}$, rather than the cement paste containing water and cement only. Hence, the paste volume should include the volume of water, the solid volume of cement and the solid volume of those fine aggregate particles smaller than $75 \mu \mathrm{m}$. For this reason, when determining the packing density of fine aggregate for the purpose of calculating the PFT, the portion of the fine aggregate smaller than $75 \mu \mathrm{m}$ has to be excluded. From the measured packing density of the remaining portion (the portion larger than $75 \mu \mathrm{m}$ ) of fine aggregate $\varphi$, the voids ratio of the remaining portion of fine aggregate $v$ can be evaluated as:

$v=\frac{1-\varphi}{\varphi}$

Having evaluated the above voids ratio, the excess paste ratio of the mortar $p_{\mathrm{w}}^{\prime}$ (defined as the ratio of the volume of excess paste to the solid volume of the remaining portion of fine aggregate) can be obtained as: 
$p_{\mathrm{w}}^{\prime}=p_{\mathrm{w}}-v$

where $p_{\mathrm{w}}$ is the paste ratio of the mortar (defined as the ratio of the volume of paste to the solid volume of the remaining portion of fine aggregate). On the other hand, the specific surface area of the remaining portion of fine aggregate (defined as the solid surface area per unit solid volume of the aggregate particles larger than $75 \mu \mathrm{m}) A_{\mathrm{FA}}^{\prime}$ can be calculated from the particle size distribution of the aggregate. With the values of $p_{\mathrm{w}}^{\prime}$ and $A_{\mathrm{FA}}^{\prime}$ so determined, the PFT, which has the physical meaning of being the average thickness of the paste films coating the aggregate particles larger than $75 \mu \mathrm{m}$, may be obtained as:

$\mathrm{PFT}=\frac{p_{\mathrm{w}}^{\prime}}{A_{\mathrm{FA}}^{\prime}}$

\section{Experimental program}

To study the roles of WFT and PFT in the rheological properties of cement-sand mortar, an experimental program was launched, in which mortar mixes with different $C / A$ and $W / C$ ratios were tested. All the $C / A$ and $W / C$ ratios were quantified in terms of volumetric ratios because the rheological properties of mortar are governed by the volumetric ratios of the ingredients rather than the weight ratios. The $C / A$ ratio was varied from 0.3 to 0.9 in steps of 0.1 , while the $W / C$ ratio was varied from 1.00 to 1.50 for mortar mixes with $C / A$ ratio $\leq 0.4$ and from 0.75 to 1.50 for mortar mixes with $C / A$ ratio $\geq 0.5$. A SP was added to each mortar sample at a constant dosage of $3 \%$ measured in terms of liquid weight of SP by weight of cement, which is the maximum dosage recommended by the supplier. For easy identification, each mortar sample was assigned a sample number of $X-Y$, where $X$ denotes the $C / A$ ratio and $Y$ denotes the $W / C$ ratio, as listed in the first column of Table 1.

All mortar samples were made by mixing the ingredients in a standard mixer complying with BS EN 196: Parts 1-3. To ensure thorough mixing, a special mixing procedure of first adding all the water to the mixer and then adding the dry solid ingredients in several increments to the mixer was adopted. This mixing procedure would lead to the sequential formation of first a slurry, then an over-saturated mixture and ultimately the final mixture. By keeping the mixture wet as far as possible, this would render easier wetting of the solid ingredients and more efficient mixing of the solid ingredients and water. It has been used by the authors' research group in previous studies [20-24] to replace the conventional mixing procedure of adding all the solid ingredients to the water in a single batch, which would encounter difficulties at low water content due to formation of dry agglomerates in the mixture. All mixing and testing procedures were executed in a laboratory maintained at a temperature of $24 \pm 2{ }^{\circ} \mathrm{C}$.

\subsection{Materials}

An ordinary Portland cement of strength class $52.5 \mathrm{~N}$ was used. It had been tested to comply with BS 12 : 1996 and measured in accordance with BS EN 196-6: 1992 to have a Blaine fineness of $354 \mathrm{~m}^{2} / \mathrm{kg}$. For the fine aggregate, crushed granite rock fine with a maximum size of $1.18 \mathrm{~mm}$ was used. Its water absorption and moisture content were measured as 1.02 and $0.41 \%$ by weight, respectively. The relative densities of the cement and fine aggregate had been measured in accordance with BS 4550: Part 3: 1978 and BS 812: Part 2: 1995 as 3.11 and 2.48, respectively. A laser diffraction particle size analyzer was employed to measure the particle size distributions of the cement and fine aggregate, as plotted in Fig. 1. From these particle size distributions, the specific surface areas of the cement, the fine aggregate (including all particles) and the fine aggregate with size larger than $75 \mu \mathrm{m}$ (excluding the portion with size smaller than $75 \mu \mathrm{m}$ ) were calculated to be $1.55 \times 10^{6}$, $1.08 \times 10^{5}$ and $1.50 \times 10^{4} \mathrm{~m}^{2} / \mathrm{m}^{3}$, respectively. To simulate the presence of SP in modern concrete, a SP was added to each mortar sample. The SP added was a polycarboxylate-based type with a solid mass content of $20 \%$ and a relative density of 1.03 .

\subsection{Measurement of flow spread and flow rate}

The mini slump cone test and mini V-funnel test were used to measure the flow spread and flow rate, respectively, of the mortar samples. Both the mini slump cone and mini $\mathrm{V}$-funnel tests for mortar may be regarded as reduced scale versions of the slump flow and V-funnel tests for concrete. There are several different versions of mini slump cone and mini V-funnel. The versions adopted in this study were the same as those used by Okamura and Ouchi [6]. Basically, the mini-slump cone used has a base 
Table 1 Flowability, rheological properties, cohesiveness and adhesiveness results

a These results were not obtained because the torque needed for measurement had exceeded the torque capacity of the rheometer

\begin{tabular}{|c|c|c|c|c|c|c|}
\hline Sample no. & $\begin{array}{l}\text { Flow spread } \\
(\mathrm{mm})\end{array}$ & $\begin{array}{l}\text { Flow rate } \\
(\mathrm{ml} / \mathrm{s})\end{array}$ & $\begin{array}{l}\text { Yield } \\
\text { stress }(\mathrm{Pa})\end{array}$ & $\begin{array}{l}\text { Apparent } \\
\text { viscosity } \\
\text { (Pas) }\end{array}$ & $\begin{array}{l}\text { SSI } \\
(\%)\end{array}$ & $\begin{array}{l}\text { Stone rod } \\
\text { adhesion } \\
(\mathrm{g})\end{array}$ \\
\hline $0.3-1.00$ & 1 & 0 & $>30^{\mathrm{a}}$ & $>30^{\mathrm{a}}$ & 0.0 & 0.0 \\
\hline $0.3-1.25$ & 42 & 4 & $>30^{\mathrm{a}}$ & $>30^{\mathrm{a}}$ & 0.0 & 4.1 \\
\hline $0.3-1.50$ & 157 & 85 & 5.39 & 7.29 & 0.7 & 18.8 \\
\hline $0.4-1.00$ & 116 & 12 & 20.30 & 28.94 & 0.0 & 2.9 \\
\hline $0.4-1.25$ & 203 & 133 & 4.57 & 6.51 & 1.8 & 20.3 \\
\hline $0.4-1.50$ & 218 & 246 & 2.50 & 3.34 & 17.2 & 10.4 \\
\hline $0.5-0.75$ & 0 & 0 & $>30^{\mathrm{a}}$ & $>30^{\mathrm{a}}$ & 0.0 & 0.0 \\
\hline $0.5-0.85$ & 0 & 0 & $>30^{\mathrm{a}}$ & $>30^{\mathrm{a}}$ & 0.0 & 0.0 \\
\hline $0.5-1.00$ & 198 & 58 & 8.42 & 11.24 & 0.0 & 33.0 \\
\hline $0.5-1.25$ & 248 & 172 & 2.93 & 4.40 & 2.8 & 14.5 \\
\hline $0.5-1.50$ & 259 & 359 & 1.42 & 0.94 & 19.5 & 9.2 \\
\hline $0.6-0.75$ & 0 & 0 & $>30^{\mathrm{a}}$ & $>30^{\mathrm{a}}$ & 0.0 & 0.0 \\
\hline $0.6-0.85$ & 64 & 25 & 25.08 & 24.35 & 0.0 & 52.8 \\
\hline $0.6-1.00$ & 264 & 130 & 4.71 & 5.99 & 0.9 & 24.1 \\
\hline $0.6-1.25$ & 276 & 269 & 1.62 & 3.59 & 15.9 & 11.4 \\
\hline $0.6-1.50$ & 314 & 440 & 1.13 & 1.44 & 38.0 & 8.1 \\
\hline $0.7-0.75$ & 4 & 0 & $>30^{\mathrm{a}}$ & $>30^{\mathrm{a}}$ & 0.0 & 0.0 \\
\hline $0.7-0.85$ & 174 & 75 & 7.16 & 11.06 & 0.0 & 42.1 \\
\hline $0.7-1.00$ & 280 & 148 & 4.14 & 5.39 & 8.6 & 14.9 \\
\hline $0.7-1.25$ & 305 & 343 & 1.12 & 2.83 & 33.9 & 6.1 \\
\hline $0.7-1.50$ & 322 & 481 & 0.38 & 1.27 & 47.2 & 5.3 \\
\hline $0.8-0.75$ & 13 & 1 & $>30^{\mathrm{a}}$ & $>30^{\mathrm{a}}$ & 0.0 & 2.8 \\
\hline $0.8-0.85$ & 197 & 86 & 4.69 & 7.29 & 0.0 & 32.2 \\
\hline $0.8-1.00$ & 289 & 169 & 1.32 & 2.68 & 23.0 & 8.3 \\
\hline $0.8-1.25$ & 317 & 383 & 0.63 & 2.05 & 37.2 & 7.0 \\
\hline $0.8-1.50$ & 343 & 545 & 0.28 & 0.27 & 50.3 & 4.7 \\
\hline $0.9-0.75$ & 116 & 33 & 19.00 & 19.61 & 0.0 & 27.8 \\
\hline $0.9-0.85$ & 238 & 123 & 3.14 & 5.47 & 5.3 & 20.0 \\
\hline $0.9-1.00$ & 280 & 208 & 0.97 & 2.54 & 52.3 & 9.8 \\
\hline $0.9-1.25$ & 313 & 431 & 0.43 & 0.46 & 58.8 & 4.4 \\
\hline $0.9-1.50$ & 283 & 659 & 0.13 & 0.82 & 93.3 & 4.0 \\
\hline
\end{tabular}

diameter of $100 \mathrm{~mm}$, a top diameter of $70 \mathrm{~mm}$ and a height of $60 \mathrm{~mm}$ whereas the mini $\mathrm{V}$-funnel used has a base opening of $30 \mathrm{~mm} \times 30 \mathrm{~mm}$, a top opening of $30 \mathrm{~mm} \times 270 \mathrm{~mm}$ and an overall height of $300 \mathrm{~mm}$. Details of the test procedures have been given in a previous paper [22].

\subsection{Measurement of rheological properties}

The vane test was used to evaluate the rheological properties of the mortar samples. For this test, a speedcontrolled rheometer equipped with a shear vane, measuring $20 \mathrm{~mm}$ in width and $40 \mathrm{~mm}$ in length, and a cylindrical container, having an inner diameter of $40 \mathrm{~mm}$, was used. The inner wall of the container was profiled with grooves whose asperity was slightly larger than the largest particle in the mortar to avoid slippage of the mortar there. As the test procedures have been given before [22], only the main features are presented herein.

At the onset of the test, the shear vane was concentrically inserted into the mortar sample in the cylindrical container and then set to rotate at controlled speed, following a sequence which consisted of 


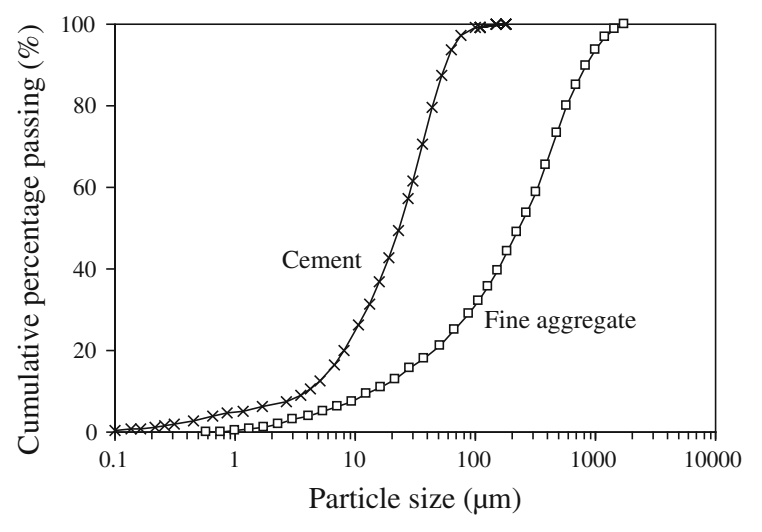

Fig. 1 Particle size distributions of cement and fine aggregate

two cycles. In each cycle, the rotation speed was increased from 0 to $50 \mathrm{rpm}$ in $75 \mathrm{~s}$ and then decreased to $0 \mathrm{rpm}$ in another $75 \mathrm{~s}$. The first cycle, called the preshearing cycle, was to apply pre-shearing so that all the samples tested had the same shearing history before measurement. The second cycle, called the data-logging cycle, was for actual measurement. During shearing, the torque induced at the shear vane was regularly logged. Only the results obtained at decreasing rotation speed in the data-logging cycle, which are generally more consistent and repeatable, were used. From these results, the variation of shear stress with shear rate was determined and a best-fit curve based on the Herschel-Bulkley model was derived by regression analysis. Then, from the best-fit curve, the yield stress (the shear stress at a shear rate of zero) and apparent viscosity (the shear stress to shear rate ratio at a shear rate of $14 \mathrm{~s}^{-1}$ ) were determined.

\subsection{Measurement of cohesiveness and adhesiveness}

The cohesiveness of the mortar samples was measured using a modified version of the sieve segregation test stipulated in the European Guidelines for SCC [28]. This modified sieve segregation test for mortar is similar to the sieve segregation test for SCC except that a smaller $1.18 \mathrm{~mm}$ sieve is used instead of the $5.0 \mathrm{~mm}$ sieve for SCC. To perform the test, an approximately 0.21 mortar sample was poured onto the $1.18 \mathrm{~mm}$ sieve from a height of $300 \mathrm{~mm}$ and then allowed to drip through the sieve. After 2 min, when the dripping should have finished, the mortar dripped through the sieve and collected by a base receiver was weighed and the sieve segregation index (SSI) of the mortar sample tested was determined as the proportion of mortar dripped through the sieve and collected by the base receiver, expressed as a percentage by mass. For a mortar with low cohesiveness, nearly all the mortar poured onto the sieve would drip through the sieve. On the contrary, for a mortar with high cohesiveness, only a small proportion of mortar or even no mortar would drip through the sieve. Based on this phenomenon, the SSI is commonly taken as an inverse measure of cohesiveness. In general, a low SSI indicates high cohesiveness whereas a high SSI indicates low cohesiveness.

A new test, called the stone rod adhesion test, was developed to measure the adhesiveness of the mortar samples. The test setup consists of six stone rods vertically fixed to a handle, as shown in Fig. 2, and a container. The stone rods are made of granite, a common rock for aggregate. Each stone rod has a diameter of $10 \mathrm{~mm}$ and an exposed length of $110 \mathrm{~mm}$. Before testing, the stone rods were pre-wetted and wiped clean to become saturated and surface dry. To perform the test, the mortar was poured into the container to a height of at least $110 \mathrm{~mm}$. Then the stone rods were immersed into the mortar until the immersion depth was equal to $100 \mathrm{~mm}$, as indicated by the mortar surface reaching the $100 \mathrm{~mm}$ mark on the stone rods. The stone rods were left immersed in the mortar for $1 \mathrm{~min}$ and afterwards pulled out steadily and slowly. As the stone rods were pulled out, some mortar adhered on the stone rods but the mortar adhered there also started dripping downwards. The handle holding the stone rods was placed

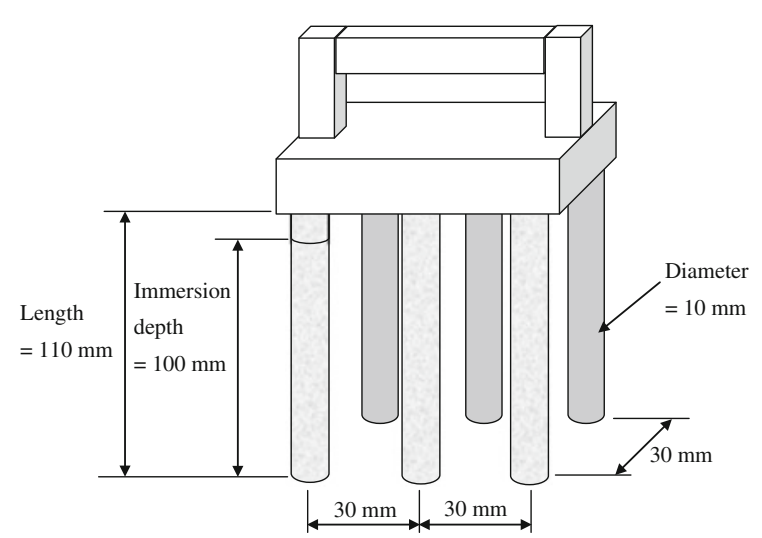

Fig. 2 Details of stone rods for adhesiveness measurement 
on a stand to allow dripping to take place. After $2 \mathrm{~min}$, when no more dripping occurred, the increase in weight of the handle (the weight of mortar adhering on the stone rods) was measured and taken as the adhesiveness of the mortar tested.

\subsection{Measurement of packing density}

The wet packing method developed by the authors' group [17-19] was used to measure the packing density of the solid particles (cement plus fine aggregate or just fine aggregate) in the mortar. To perform the test, six to eight samples having the same mix proportions of solid particles and the same SP dosage but different water contents (ranging from insufficient to more than sufficient to fill the voids between solid particles) were produced and their respective solid concentrations were measured. In general, as the water content increased, the solid concentration first increased with the water content to a maximum value and then decreased. The maximum solid concentration so obtained was taken as the packing density of the solid particles. In this particular study, since the $C / A$ ratio varied from 0.3 to 0.9 in steps of 0.1 , the 31 mortar samples tested for their rheological properties were actually made from seven different mix proportions of cement and fine aggregate. Hence, only seven mix proportions of cement and fine aggregate were tested for their packing densities. In addition, to determine the PFT, the packing density of the portion of fine aggregate with size larger than $75 \mu \mathrm{m}$ was also measured.

\section{Experimental results}

\subsection{Flow spread and flow rate}

The flow spread and flow rate results of the mortar samples are tabulated in the second and third columns of Table 1, and plotted against the $C / A$ ratio for different $W / C$ ratios in Figs. 3 and 4, respectively. It is noted from Fig. 3 that at all $W / C$ ratios, the flow spread increased with increasing $C / A$ ratio until it reached about $300 \mathrm{~mm}$ to $350 \mathrm{~mm}$. Moreover, the flow spread was generally higher at a higher $W / C$ ratio. On the other hand, it is noted from Fig. 4 that at all $W / C$ ratios, the flow rate increased with increasing $C / A$ ratio at a

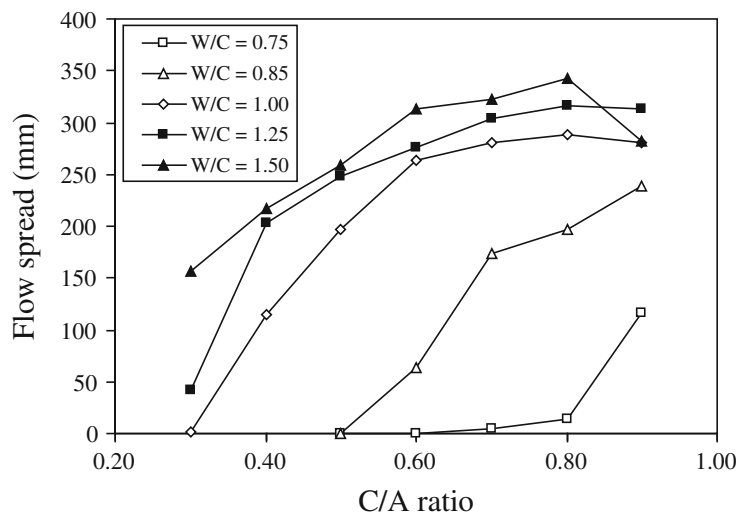

Fig. 3 Flow spread versus $C / A$ ratio

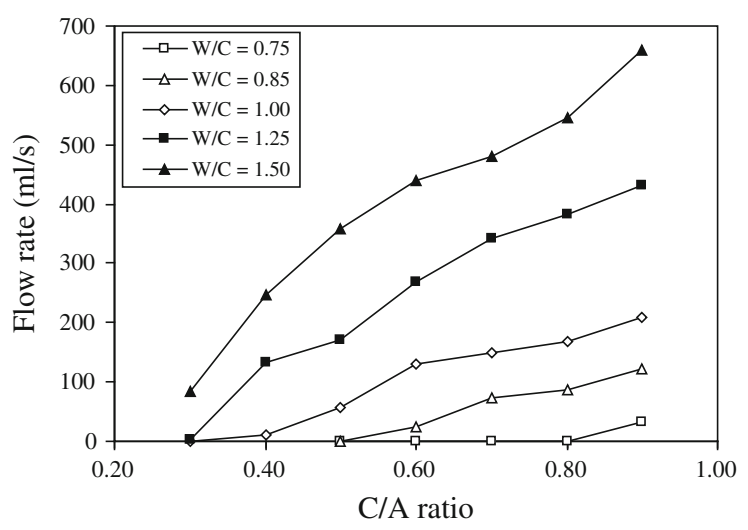

Fig. 4 Flow rate versus $C / A$ ratio

more or less constant rate. The flow rate was also generally higher at a higher $W / C$ ratio. These observed phenomena are reasonable because increasing the $C / A$ ratio and/or $W / C$ ratio would increase the water content and thus should always increase the flowability of the mortar.

\subsection{Yield stress and apparent viscosity}

The yield stress and apparent viscosity results of the mortar samples are tabulated in the fourth and fifth columns of Table 1 , and plotted against the $C / A$ ratio for different $W / C$ ratios in Figs. 5 and 6, respectively. From the curves plotted, it can be seen that both the yield stress and apparent viscosity gradually decreased as the $C / A$ ratio increased. Moreover, at the same $C / A$ ratio, both the yield stress and apparent viscosity were lower at a higher $W / C$ ratio. In other words, both the yield stress and 


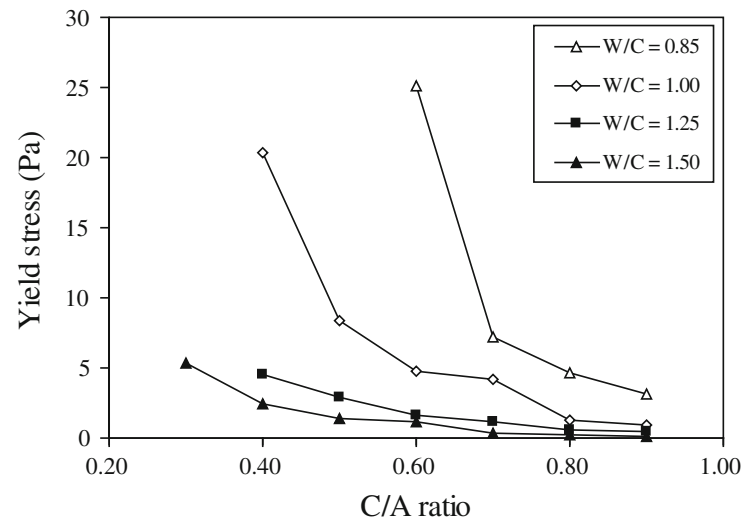

Fig. 5 Yield stress versus $C / A$ ratio

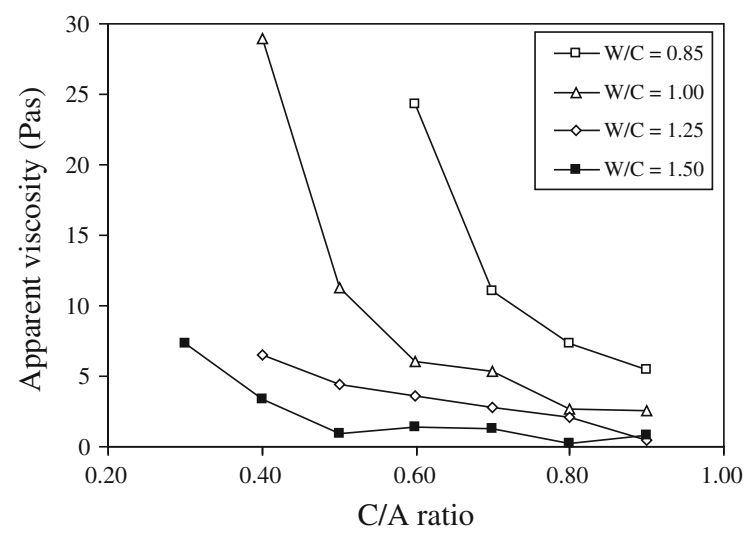

Fig. 6 Apparent viscosity versus $C / A$ ratio

apparent viscosity decreased with increasing $C / A$ ratio and/or increasing $W / C$ ratio. This was because as the $C / A$ ratio and/or $W / C$ ratio increased, the water content increased and as a result the shear resistance of the mortar decreased.

\subsection{Cohesiveness and adhesiveness}

The SSI results of the mortar samples are tabulated in the sixth column of Table 1 and plotted against the $C / A$ ratio for different $W / C$ ratios in Fig. 7. It is seen that when the $C / A$ ratio was relatively low, the SSI remained at around zero and then when the $C / A$ ratio exceeded a certain value depending on the $W / C$ ratio, the SSI started to increase with the $C / A$ ratio. At a higher $W / C$ ratio, the $C / A$ ratio at which the SSI started to increase was lower, leading to a higher SSI at the same $C / A$ ratio. Hence, the cohesiveness is generally lower at higher $C / A$ ratio and/or higher $W / C$ ratio. This

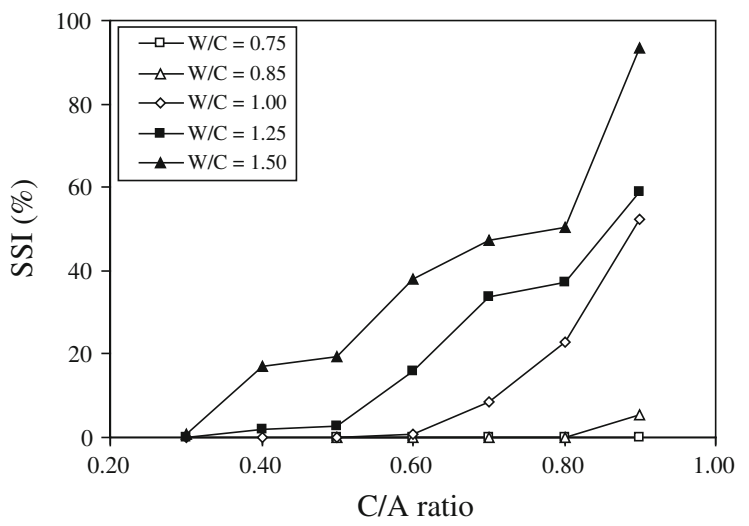

Fig. 7 Sieve segregation index versus $C / A$ ratio

can be easily explained, as increasing the $C / A$ ratio and/or $W / C$ ratio would increase the water content and thus produce a less cohesive mortar.

The adhesiveness results of the mortar samples are tabulated in the last column of Table 1 and plotted against the $C / A$ ratio for different $W / C$ ratios in Fig. 8. It is seen that at the same $W / C$ ratio, the adhesiveness varied with the $C / A$ ratio in such a way that when the $C / A$ ratio was relatively low, the adhesiveness increased as the $C / A$ ratio increased, but after reaching a certain peak value, the adhesiveness decreased as the $C / A$ further increased. The peak value of adhesiveness varied with the $W / C$ ratio and appeared to be highest at a $W / C$ ratio of 0.85 . This implies that the water added to a mortar may have positive or negative effects on the adhesiveness and there is an optimum water content depending on the mix proportions of the solid ingredients for maximum adhesiveness. Further analysis will be presented later.

\section{Roles of packing density, excess water ratio and solid surface area}

The packing density results of the seven mixes of cement and fine aggregate tested are tabulated in the second column of Table 2. These results show that the packing density varied significantly with the $C / A$ ratio. As the $C / A$ ratio increased from 0.3 to 0.4 , the packing density increased from 0.767 to a peak value of 0.770 . Then, as the $C / A$ ratio further increased from 0.4 to 0.9 , the packing density gradually decreased from the peak value of 0.770 to 0.743 . Hence, there existed an optimum $C / A$ ratio 


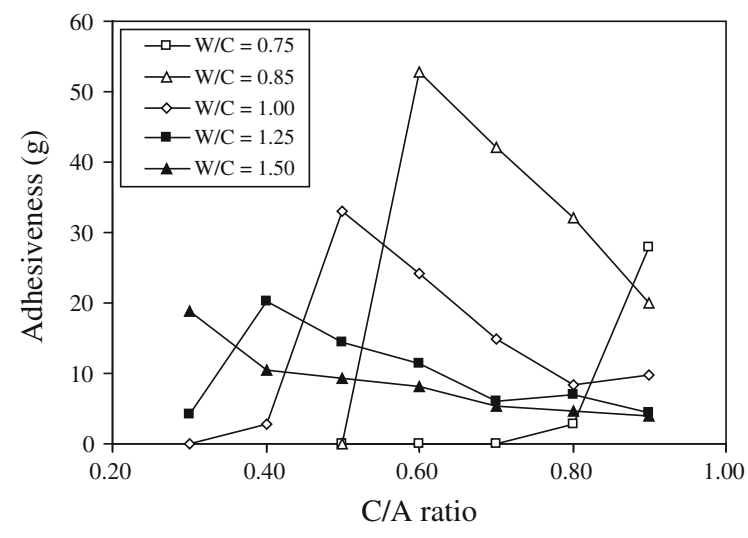

Fig. 8 Adhesiveness versus $C / A$ ratio

at which the packing density was highest. This phenomenon can be explained using the packing theory [26]. When the $C / A$ ratio is low, the cement would fill into the voids between the aggregate particles to increase the packing density, but when the $C / A$ ratio is high, the cement would become more than enough to fill the voids and further addition of cement would only push the aggregate particles apart causing the packing density to decrease. The maximum packing density should occur when the cement is just enough to fill the voids between the aggregate particles. On the other hand, the packing density of the portion of fine aggregate larger than $75 \mu \mathrm{m}$ was measured as 0.631 . This result is tabulated in the second column of Table 3.

As the water added has to first fill up the voids between the solid particles and it is the excess water that lubricates the solid particles, an increase in packing density would reduce the amount of voids to be filled, increase the volume of excess water and finally improve the flowability and rheology of the water-solid mixture. In the present case, although the range of packing density was not large, the change in packing density did have significant effects. This can be seen from the calculated excess water ratio of each mortar sample tabulated in the third column of Table 2. On the other hand, in a mortar mix, the water, cement and portion of fine aggregate smaller than $75 \mu \mathrm{m}$ would together form the paste. The paste has to first fill up the voids between the larger aggregate particles and it is the excess paste that lubricates the larger aggregate particles. Hence, increasing the volume of excess paste can also enhance the flowability and rheology of the mortar. The calculated excess paste ratios of the mortar samples tested are tabulated in the third column of Table 3.

However, the excess water ratio and excess paste ratio are not the only factors affecting the flowability and rheology of mortar. Since the excess water and excess paste would be spread out to cover solid surfaces and a larger solid surface area would lead to thinner water films or paste films, the solid surface areas should also have some effects. To study the effects of the solid surface areas, the specific surface areas of the seven mixes of cement and fine aggregate tested and the specific surface area of the fine aggregate larger than $75 \mu \mathrm{m}$ are calculated from the particle size distributions of the cement and fine aggregate, and tabulated in the fourth column of Table 2 and the fourth column of Table 3, respectively. From these results, the average WFT may be determined as the excess water ratio divided by the specific surface area of the cement plus fine aggregate and the average PFT may be determined as the excess paste ratio divided by the specific surface area of the fine aggregate larger than $75 \mu \mathrm{m}$, as tabulated in the last column of Table 2 and the last column of Table 3, respectively. For brevity, the average WFT and average PFT are hereafter referred to simply as the WFT and the PFT, respectively.

\section{Roles of WFT and PFT}

The WFT results reveal that for the mortar samples tested with $C / A$ ratios ranging from 0.3 to 0.9 and $W /$ $C$ ratios ranging from 0.75 to 1.50 , the WFT ranged from -0.168 to $0.460 \mu \mathrm{m}$ (a negative WFT means that the water added was not sufficient to fill up the voids). To better illustrate how the WFT is related to the $C / A$ ratio and $W / C$ ratio, the WFT is plotted against the $C / A$ ratio for different $W / C$ ratios in Fig. 9. It is seen that the WFT increased with both the $C / A$ ratio and $W / C$ ratio. When the $C / A$ ratio was relatively low $(C / A$ ratio $\leq 0.4)$, the WFT increased sharply with the $C / A$ ratio but when the $C / A$ ratio was relatively high $(C / A$ ratio $\geq 0.5)$, the WFT increased only steadily with the $C / A$ ratio. Moreover, at all $C / A$ ratios, the WFT increased more or less linearly with the $W / C$ ratio. On the other hand, the PFT results ranged from 42.4 to $194.8 \mu \mathrm{m}$. They are plotted against the 
Table 2 Water film thickness of mortar samples

\begin{tabular}{|c|c|c|c|c|}
\hline Sample no. & $\begin{array}{l}\text { Packing density } \\
\text { of solid particles }\end{array}$ & Excess water ratio & $\begin{array}{l}\text { Specific surface area } \\
\text { of solid particles }\left(\mathrm{m}^{2} / \mathrm{m}^{3}\right)\end{array}$ & $\begin{array}{l}\text { Water film } \\
\text { thickness }(\mu \mathrm{m})\end{array}$ \\
\hline $0.3-1.00$ & 0.767 & -0.074 & 440,536 & -0.168 \\
\hline $0.3-1.25$ & & -0.016 & & -0.036 \\
\hline $0.3-1.50$ & & 0.042 & & 0.095 \\
\hline $0.4-1.00$ & 0.770 & -0.013 & 519,785 & -0.025 \\
\hline $0.4-1.25$ & & 0.058 & & 0.112 \\
\hline $0.4-1.50$ & & 0.130 & & 0.250 \\
\hline $0.5-0.75$ & 0.757 & -0.071 & 588,468 & -0.121 \\
\hline $0.5-0.85$ & & -0.038 & & -0.065 \\
\hline $0.5-1.00$ & & 0.012 & & 0.020 \\
\hline $0.5-1.25$ & & 0.096 & & 0.163 \\
\hline $0.5-1.50$ & & 0.179 & & 0.304 \\
\hline $0.6-0.75$ & 0.754 & -0.045 & 648,566 & -0.069 \\
\hline $0.6-0.85$ & & -0.008 & & -0.012 \\
\hline $0.6-1.00$ & & 0.048 & & 0.074 \\
\hline $0.6-1.25$ & & 0.142 & & 0.219 \\
\hline $0.6-1.50$ & & 0.236 & & 0.364 \\
\hline $0.7-0.75$ & 0.751 & -0.023 & 701,593 & -0.033 \\
\hline $0.7-0.85$ & & 0.018 & & 0.026 \\
\hline $0.7-1.00$ & & 0.080 & & 0.114 \\
\hline $0.7-1.25$ & & 0.183 & & 0.261 \\
\hline $0.7-1.50$ & & 0.285 & & 0.406 \\
\hline $0.8-0.75$ & 0.746 & -0.007 & 748,728 & -0.009 \\
\hline $0.8-0.85$ & & 0.037 & & 0.049 \\
\hline $0.8-1.00$ & & 0.104 & & 0.139 \\
\hline $0.8-1.25$ & & 0.215 & & 0.287 \\
\hline $0.8-1.50$ & & 0.326 & & 0.435 \\
\hline $0.9-0.75$ & 0.743 & 0.009 & 790,902 & 0.011 \\
\hline $0.9-0.85$ & & 0.056 & & 0.071 \\
\hline $0.9-1.00$ & & 0.127 & & 0.161 \\
\hline $0.9-1.25$ & & 0.245 & & 0.310 \\
\hline $0.9-1.50$ & & 0.364 & & 0.460 \\
\hline
\end{tabular}

$C / A$ ratio for different $W / C$ ratios in Fig. 10. It is observed that the PFT increased with both the $C / A$ ratio and $W / C$ ratio at a more or less constant rate. Such variations of the WFT and PFT with the $C / A$ ratio and $W / C$ ratio are in fact the combined effects of the corresponding changes in water or paste content, packing density and specific surface area. On the whole, the WFT or PFT would increase when the percentage increase in excess water ratio or excess paste ratio is larger than the percentage increase in specific surface area, and vice versa. Increasing the packing density without excessively increasing the solid surface area is the best way of increasing the WFT and PFT.

\subsection{Effects of WFT and PFT on flow spread}

By plotting the flow spread against the WFT as shown in Fig. 11, it can be seen that in general, the flow spread increased with the WFT at a decreasing rate until the flow spread reached about $300 \mathrm{~mm}$ to $350 \mathrm{~mm}$. On the whole, the flow spread varied mainly with the WFT and therefore the WFT should be a major factor affecting the flow spread of mortar. However, the data points show that at the same WFT, a mortar having a thicker PFT has a slightly larger flow spread, indicating that the PFT also has certain effect on the flow spread. In order to investigate the 
Table 3 Paste film thickness of mortar samples

\begin{tabular}{|c|c|c|c|c|}
\hline Sample no. & $\begin{array}{l}\text { Packing density } \\
\text { of aggregate } \\
\text { larger than } 75 \mu \mathrm{m}\end{array}$ & $\begin{array}{l}\text { Excess paste } \\
\text { ratio }\end{array}$ & $\begin{array}{l}\text { Specific surface } \\
\text { area of aggregate } \\
\text { larger than } 75 \mu \mathrm{m} \\
\left(\mathrm{m}^{2} / \mathrm{m}^{3}\right)\end{array}$ & $\begin{array}{l}\text { Paste film } \\
\text { thickness }(\mu \mathrm{m})\end{array}$ \\
\hline $0.3-1.00$ & 0.631 & 0.637 & 15,035 & 42.4 \\
\hline $0.3-1.25$ & & 0.742 & & 49.4 \\
\hline $0.3-1.50$ & & 0.846 & & 56.3 \\
\hline $0.4-1.00$ & 0.631 & 0.915 & 15,035 & 60.9 \\
\hline $0.4-1.25$ & & 1.054 & & 70.1 \\
\hline $0.4-1.50$ & & 1.193 & & 79.3 \\
\hline $0.5-0.75$ & 0.631 & 1.019 & 15,035 & 67.8 \\
\hline $0.5-0.85$ & & 1.089 & & 72.4 \\
\hline $0.5-1.00$ & & 1.193 & & 79.3 \\
\hline $0.5-1.25$ & & 1.367 & & 90.9 \\
\hline $0.5-1.50$ & & 1.540 & & 102.4 \\
\hline $0.6-0.75$ & 0.631 & 1.262 & 15,035 & 83.9 \\
\hline $0.6-0.85$ & & 1.346 & & 89.5 \\
\hline $0.6-1.00$ & & 1.471 & & 97.8 \\
\hline $0.6-1.25$ & & 1.679 & & 111.7 \\
\hline $0.6-1.50$ & & 1.887 & & 125.5 \\
\hline $0.7-0.75$ & 0.631 & 1.505 & 15,035 & 100.1 \\
\hline $0.7-0.85$ & & 1.603 & & 106.6 \\
\hline $0.7-1.00$ & & 1.749 & & 116.3 \\
\hline $0.7-1.25$ & & 1.992 & & 132.5 \\
\hline $0.7-1.50$ & & 2.235 & & 148.7 \\
\hline $0.8-0.75$ & 0.631 & 1.749 & 15,035 & 116.3 \\
\hline $0.8-0.85$ & & 1.860 & & 123.7 \\
\hline $0.8-1.00$ & & 2.026 & & 134.8 \\
\hline $0.8-1.25$ & & 2.304 & & 153.2 \\
\hline $0.8-1.50$ & & 2.582 & & 171.7 \\
\hline $0.9-0.75$ & 0.631 & 1.992 & 15,035 & 132.5 \\
\hline $0.9-0.85$ & & 2.117 & & 140.8 \\
\hline $0.9-1.00$ & & 2.304 & & 153.2 \\
\hline $0.9-1.25$ & & 2.617 & & 174.1 \\
\hline $0.9-1.50$ & & 2.929 & & 194.8 \\
\hline
\end{tabular}

combined effects of WFT and PFT, multi-variable regression analysis has been carried out to derive the best-fit curves for the flow spread-WFT relation at different PFT. For comparison and easy reference, the best-fit curves so obtained are plotted alongside the data points, and the equation of the best-fit curves and its $R^{2}$ value are printed in the graph. It can be seen that as the PFT increases, the best-fit curve shifts upwards to yield a larger flow spread at the same WFT. This phenomenon is reasonable, as the paste films would provide lubrication and reduce the particle interaction between the aggregate particles. A fairly high $R^{2}$ value of 0.911 has been achieved, indicating that the flow spread is governed by both the WFT and PFT.

\subsection{Effects of WFT and PFT on flow rate}

By plotting the flow rate against the WFT as shown in Fig. 12, it can be seen that in general, when the WFT was negative, the flow rate remained very close to zero but once the WFT became positive, the flow rate 


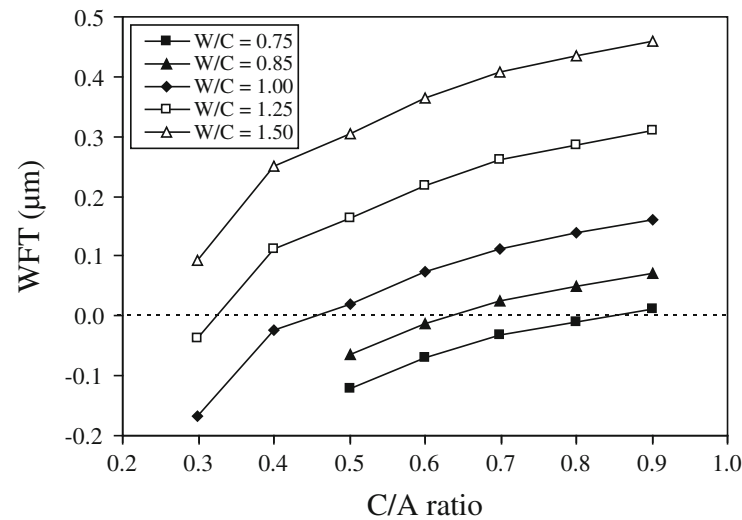

Fig. 9 WFT versus $C / A$ ratio

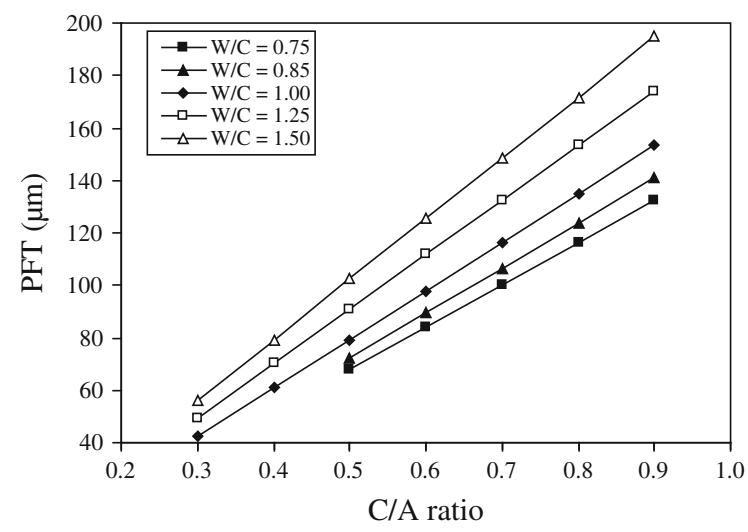

Fig. 10 PFT versus $C / A$ ratio

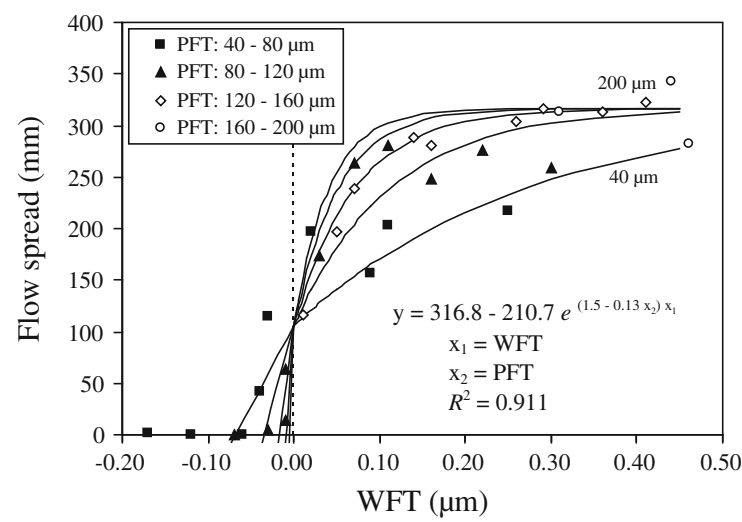

Fig. 11 Effects of WFT and PFT on flow spread

increased with the WFT at a more or less constant rate. More importantly, the data points are lying within a narrow band, showing that the WFT should be a key factor governing the flow rate of mortar. Despite the high correlation between flow rate and WFT, it

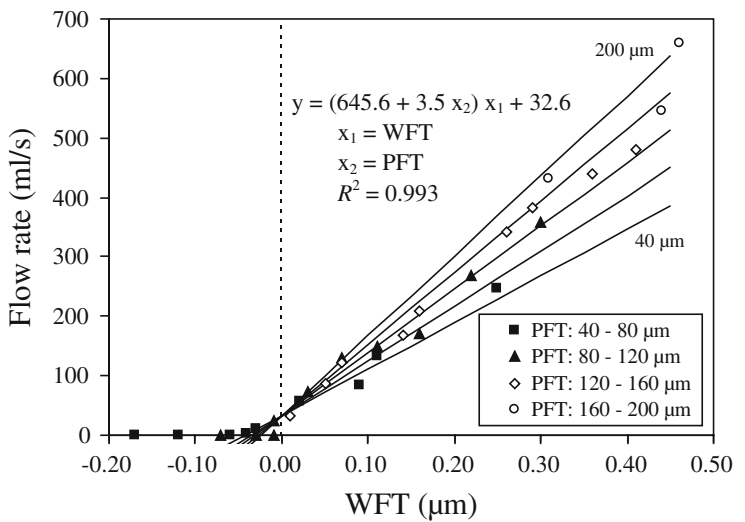

Fig. 12 Effects of WFT and PFT on flow rate

appears that at the same WFT, the flow rate also increases slightly with the PFT. To study the combined effects of WFT and PFT, multi-variable regression analysis has been carried out to derive the best-fit curves for the flow rate-WFT relation at different PFT. The best-fit curves so obtained are plotted alongside the data points, and the equation of the curves and its $R^{2}$ value are printed in the graph. From the figure, it is obvious that as the PFT increases, the best-fit curve rotates anti-clockwise such that the flow rate would increase with the WFT at a faster rate. The causes of the increase in flow rate with PFT should be similar to those of the increase in flow spread with PFT. A very high $R^{2}$ value of 0.993 has been achieved, implying that with both the WFT and PFT considered, the flow rate can be predicted quite accurately.

\subsection{Effects of WFT and PFT on yield stress}

The yield stress is plotted against the WFT in Fig. 13 to illustrate how the yield stress varied with the WFT. In general, the yield stress decreased as the WFT increased. This phenomenon is expected because a water-solid mixture with a larger WFT should require a smaller shear stress to flow. Furthermore, the data points are lying within a narrow band, indicating that the yield stress should be governed mainly by the WFT. However, when the WFT is smaller than $0.25 \mu \mathrm{m}$, the yield stress appears to be dependent not only on the WFT but also on the PFT. To study the combined effects of WFT and PFT, multi-variable regression analysis has been carried out to derive the best-fit curves for the yield stress-WFT relation at different PFT. The best-fit curves so obtained and their 


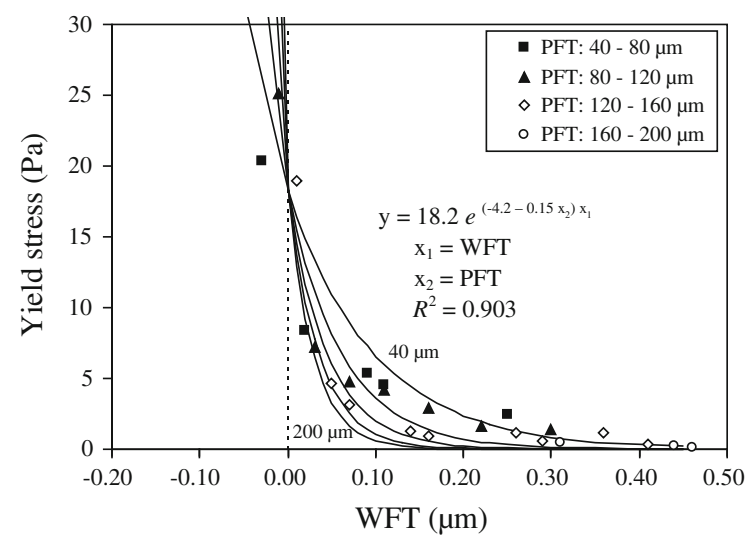

Fig. 13 Effects of WFT and PFT on yield stress

equation and $R^{2}$ value are all presented in the figure. It is noted that as the PFT increases, the best-fit curve shifts downwards such that the yield stress would be smaller. This may be explained by the paste film effects of lubricating the mortar mix and reducing the particle interaction between the aggregate particles. A fairly high $R^{2}$ value of 0.903 has been achieved, showing that the WFT and PFT together would more or less govern the yield stress.

\subsection{Effects of WFT and PFT on apparent viscosity}

The apparent viscosity is plotted against the WFT in Fig. 14 to illustrate how the apparent viscosity varied with the WFT. In general, as for the yield stress, the apparent viscosity decreased as the WFT increased. As in previous case, the data points are lying within a narrow band, indicating that the apparent viscosity should be governed mainly by the WFT. However, the

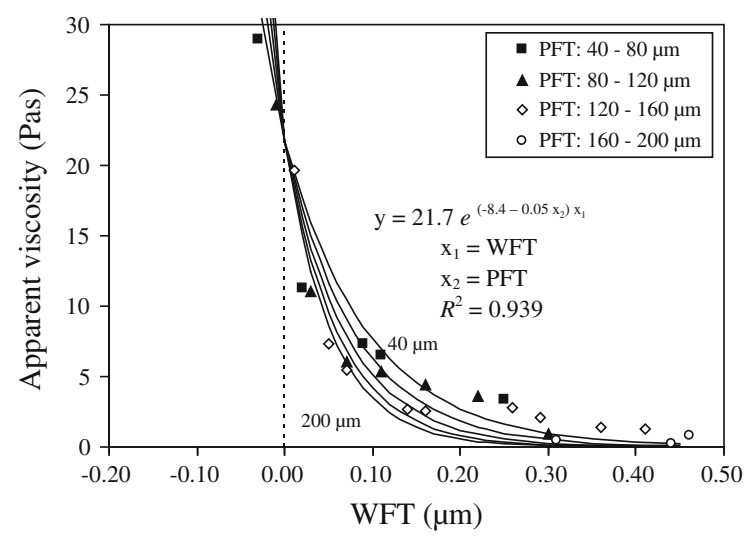

Fig. 14 Effects of WFT and PFT on apparent viscosity
PFT also has certain effect on the apparent viscosity, especially when the WFT is smaller than $0.25 \mu \mathrm{m}$. To study the combined effects of WFT and PFT, multivariable regression analysis has been carried out to derive the best-fit curves for the apparent viscosityWFT relation at different PFT. The best-fit curves so obtained and their equation and $R^{2}$ value are all presented in the figure. It is noted that as the PFT increases, the best-fit curve shifts downwards leading to lower apparent viscosity at the same WFT. The causes of such decrease in apparent viscosity should be similar to those of the decrease in yield stress with PFT. A very high $R^{2}$ value of 0.939 has been achieved, showing that the WFT and PFT together would govern the apparent viscosity.

\subsection{Effects of WFT and PFT on cohesiveness}

The SSI is plotted against the WFT in Fig. 15 to illustrate how the SSI varied with the WFT. In general, when the WFT was smaller than $0.05 \mu \mathrm{m}$, the SSI remained very close to zero but once the WFT became larger than $0.05 \mu \mathrm{m}$, the SSI started to increase with the WFT. In other words, when the WFT was very small or even negative, the mortar was very cohesive but when the WFT was larger than about $0.05 \mu \mathrm{m}$, the cohesiveness of the mortar decreased as the WFT increased. Hence, although increasing the WFT would increase the flowability and improve the rheology of the mortar, this would also reduce the cohesiveness of the mortar, which is needed to avoid segregation. From the figure, it is also observed that at the same WFT, the SSI increases markedly with the PFT, implying that the SSI is dependent not only on the

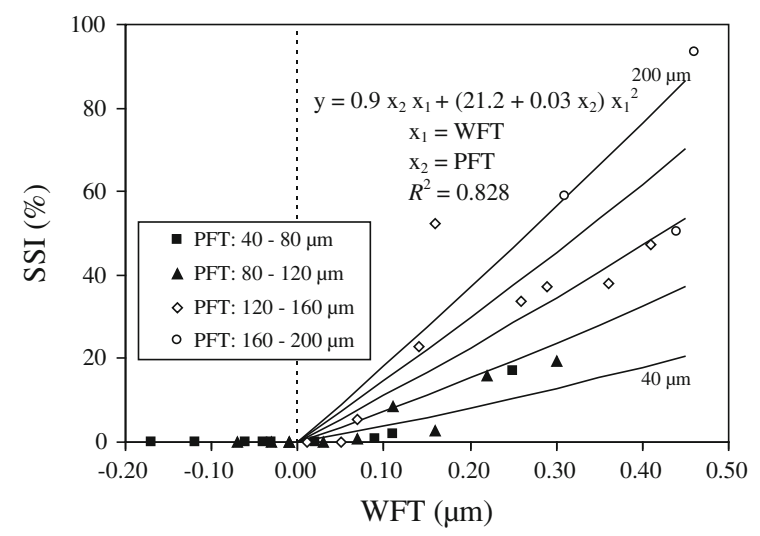

Fig. 15 Effects of WFT and PFT on SSI 
WFT but also on the PFT. To investigate the combined effects of WFT and PFT, multi-variable regression analysis has been carried out to derive the best-fit curves for the SSI-WFT relation at different PFT. The best-fit curves so obtained and their equation and $R^{2}$ value are also presented in the figure. It is seen that as the PFT increases, the best-fit curve rotates anticlockwise such that the SSI would increase with the WFT at faster rate. With both the WFT and PFT considered in the correlation, a reasonably good $R^{2}$ value of 0.828 has been achieved.

\subsection{Effects of WFT and PFT on adhesiveness}

The adhesiveness is plotted against the WFT in Fig. 16 to illustrate how the adhesiveness varied with the WFT. When the WFT was negative, the mortar appeared to be rather dry and the adhesiveness was negligibly small and unreliable. As the WFT increased to become positive, the mortar became slightly wetter and the adhesiveness increased dramatically to a certain maximum value depending on the PFT. Then, as the WFT further increased, the mortar became rather wet and the adhesiveness gradually decreased. Hence, the adhesiveness should be dependent mainly on the WFT and to a lesser extent on the PFT. To study the combined effects of WFT and PFT, multi-variable regression analysis has been carried out to derive the best-fit curves for the adhesiveness-WFT relation within the positive range of the WFT at different PFT. The best-fit curves so obtained and their equation and $R^{2}$ value are also presented in the figure. It is noted that as the PFT increases, the best-fit curve shifts

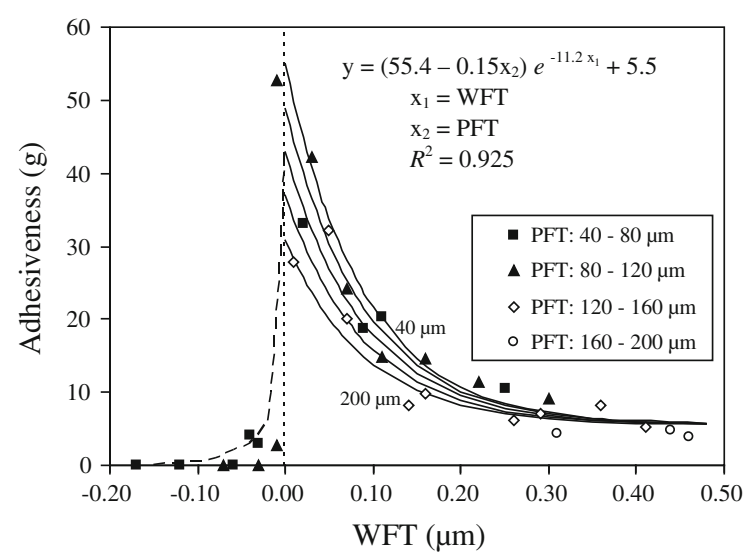

Fig. 16 Effects of WFT and PFT on adhesiveness downwards leading to lower adhesiveness at the same WFT. A very high $R^{2}$ value of 0.925 has been achieved, revealing that the adhesiveness is dependent mainly on the WFT and PFT.

From the above results, it can be seen that the adhesiveness is highest when the WFT and PFT are positive and very small. Figure 16 shows that to achieve a high adhesiveness, the WFT should be within the range of $0.01-0.10 \mu \mathrm{m}$ and the PFT should be within the range of 40-120 $\mu \mathrm{m}$. Hence, a relatively high adhesiveness would be achieved when the WFT is just sufficient to provide a thin film of water coating every solid particle and the PFT is just sufficient to provide a thin film of paste coating every aggregate particle. A possible reason is that it is always the water films and paste films that hold the mortar mix together and provide adhesion to external surfaces. Therefore, positive WFT and PFT are needed to provide adhesion. But, when the WFT and/or PFT are relatively large, the aggregate particles in the mortar mix would tend to drip downwards dragging the mortar down with them and leaving behind a relatively small proportion of mortar staying adhered to the external surfaces. For plasters, tile adhesives and repair mortars to be applied to vertical and bottom surfaces, this is an important issue because a mortar lack of adhesiveness would simply fall down after application. For this reason, the WFT and PFT of mortar mixes to be used as plasters, tile adhesives and repair mortars must be carefully designed to provide the high adhesiveness needed for application.

\section{Conclusions}

A series of mortar samples with varying $C / A$ and $W / C$ ratios were made for packing density, flowability, rheology, cohesiveness and adhesiveness measurements by the wet packing test, the mini slump cone/ mini V-funnel tests, the vane test using a rheometer, the sieve segregation test and a newly developed stone rod adhesion test. On the whole, the test results revealed that the $C / A$ ratio has significant effects on the packing density of mortar whereas both the $C / A$ and $W / C$ ratios have major effects on the flowability, rheology, cohesiveness and adhesiveness of mortar.

In-depth analysis showed that the apparently complicated effects of the $C / A$ and $W / C$ ratios are actually caused by the corresponding changes in the packing 
density, excess water ratio, excess paste ratio and solid surface area. Nevertheless, the combined effects of the packing density, excess water ratio, excess paste ratio and solid surface area may be evaluated in terms of the WFT and PFT of the mortar. Correlations of the flow spread, flow rate, yield stress, apparent viscosity, SSI and adhesiveness to the WFT and PFT by regression analysis yielded $R^{2}$ values of $0.911,0.993,0.903$, $0.939,0.828$ and 0.925 , respectively. Such high $R^{2}$ values proved that the WFT and PFT are the key factors governing the flowability, rheology, cohesiveness and adhesiveness of mortar. However, the WFT is still the single most important factor governing the fresh properties of mortar.

Lastly, the PFT has been identified as another factor that would affect the fresh properties of mortar. It has to be positive so that there would be sufficient paste to fill the voids and form paste films coating the aggregate particles. A relatively large PFT would lead to higher flowability but lower cohesiveness and adhesiveness whereas a relatively small PFT would lead to lower flowability but higher cohesiveness and adhesiveness. Hence, the PFT is also an important factor to be considered in mortar and concrete mix designs. In any case, when determining the PFT to be adopted, there is a need to strike a balance between the flowability requirement and the cohesiveness and adhesiveness requirements.

Acknowledgments The work described in this paper was fully supported by a grant from the Research Grants Council of the Hong Kong Special Administrative Region, China (Project No. 713309).

Open Access This article is distributed under the terms of the Creative Commons Attribution License which permits any use, distribution, and reproduction in any medium, provided the original author(s) and the source are credited.

\section{References}

1. Aïtcin P-C (1998) High-performance concrete. E\&FN Spon, London

2. Domone P (2006) Mortar tests for self-consolidating concrete. Concr Int 28(4):39-45

3. Lachemi M, Hossain KMA, Patel R, Shehata M, Bouzoubaâ N (2007) Influence of paste/mortar rheology on the flow characteristics of high-volume fly ash self-consolidating concrete. Mag Concr Res 59(7):517-528

4. Ng IYT, Ng PL, Kwan AKH (2009) Rheology of mortar and its influences on performance of self-consolidating concrete. Key Eng Mater 400-402:421-426
5. Billberg P (1999) Fine mortar rheology in mix design of SCC. In: Skarendahl A, Petersson Ö (eds) Proceedings of 1st international RILEM symposium on selfcompacting concrete. RILEM Publications SARL, Stockholm, pp 47-58

6. Okamura H, Ouchi M (2003) Self-compacting concrete. J Adv Concr Technol 1(1):5-15

7. Safawi MI, Iwaki I, Miura T (2004) The segregation tendency in the vibration of high fluidity concrete. Cem Concr Res 34(2):219-226

8. Gołaszewski J, Szwabowski J (2004) Influence of superplasticizers on rheological behaviour of fresh cement mortars. Cem Concr Res 34(2):235-248

9. Chen PW, Fu X, Chung DDL (1995) Improving the bonding between old and new concrete by adding carbon fibers to the new concrete. Cem Concr Res 25(3):491-496

10. Felekoğlu B, Tosun K, Baradan B, Altun A, Uyulgan B (2006) The effect of fly ash and limestone fillers on the viscosity and compressive strength of self-compacting repair mortars. Cem Concr Res 36(9):1719-1726

11. Rodriguez Á, Manso JM, Aragón Á, Gonzalez JJ (2009) Strength and workability of masonry mortars manufactured with ladle furnace slag. Resour Conserv Recycl 53(11):645651

12. Banfill PFG (1994) Rheological methods for assessing the flow properties of mortar and related materials. Constr Build Mater 8(1):43-50

13. De Schutter G, Poppe AM (2004) Quantification of the water demand of sand in mortar. Constr Build Mater 18(7):517-521

14. Reddy BVV, Gupta A (2008) Influence of sand grading on the characteristics of mortars and soil-cement block masonry. Constr Build Mater 22(8):1614-1623

15. Kwan AKH, Wong HHC (2008) Packing density of cementitious materials: part 2-packing and flow of OPC + PFA + CSF. Mater Struct 41(4):773-784

16. Svarovsky L (1987) Powder testing guide: methods of measuring the physical properties of bulk powders. Elsevier Applied Science, London

17. Wong HHC, Kwan AKH (2008) Packing density of cementitious materials: part $1-$ measurement using a wet packing method. Mater Struct 41(4):689-701

18. Fung WWS, Kwan AKH, Wong HHC (2009) Wet packing of crushed rock fine aggregate. Mater Struct 42(5):631-643

19. Kwan AKH, Fung WWS (2009) Packing density measurement and modelling of fine aggregate and mortar. Cem Concr Compos 31(6):349-357

20. Kwan AKH, Wong HHC (2008) Effects of packing density, excess water and solid surface area on flowability of cement paste. Adv Cem Res 20(1):1-11

21. Wong HHC, Kwan AKH (2008) Rheology of cement paste: role of excess water to solid surface area ratio. J Mater Civ Eng 20(2):189-197

22. Kwan AKH, Fung WWS, Wong HHC (2010) Water film thickness, flowability and rheology of cement-sand mortar. Adv Cem Res 22(1):3-14

23. Fung WWS, Kwan AKH (2010) Role of water film thickness in rheology of CSF mortar. Cem Concr Compos 32(4):255-264

24. Li LG, Kwan AKH (2011) Mortar design based on water film thickness. Constr Build Mater 25(5):2381-2390 
25. Kennedy CT (1940) The design of concrete mixes. ACI Proc 36(2):373-400

26. Powers TC (1968) The properties of fresh concrete. Wiley, New York

27. Oh SG, Noguchi T, Tomosawa F (1999) Toward mix design for rheology of self-compacting concrete. In: Skarendahl $\AA$,
Petersson Ö (eds) Proceedings of 1st international RILEM symposium on self-compacting concrete. RILEM Publications SARL, Stockholm, pp 361-372

28. SCC European Project Group (2005) The European guidelines for self-compacting concrete. BIBM, CEMBUREAU, EFCA, EFNARC and ERMCO, p 63 